\title{
Mapeamento do Patrimônio Histórico e Cultural de Cuiabá-MT: tecnologias aplicadas, representatividade e história
}

\author{
Mapping of Historical and Cultural Patrimony of Cuiabá-MT: applied technologies, \\ representativeness and history
}

Mapeo del Patrimonio Histórico y Cultural de Cuiabá-MT: tecnologías aplicadas, representatividad e historia

Franciele Cavalheiro Novack Acadêmica do Curso de Arquitetura e Urbanismo, UNIVAG, Brasil frannovack1@gmail.com

Mariane dos Santos Freitas da Silva Nobre Acadêmica do Curso de Arquitetura e Urbanismo, UNIVAG, Brasil marianenobre2018@gmai.com

Cézar Clemente Professor Mestre, UNIVAG - Centro Universitário, Brasil. cézarbiologo@gmail.com 


\section{RESUMO}

As mais variadas alternativas tecnológicas vêm surgindo para auxiliar o desenvolvimento de estudos e levantamento de dados e produtos que sirvam de subsídio à diversos tipos de projetos de diversas áreas. Uma destas alternativas é a utilização de sistemas de informações geográficas para o mapeamento e análises espaciais, principalmente no que se refere a estudo em um espaço geográfico muito extenso. O sensoriamento remoto é um importante instrumento na efetivação destes estudos e na elaboração de mapas com o uso de dados de satélite, o que facilita o alcance dos resultados a serem aplicados na arquitetura e urbanismo. O trabalho objetivou o mapeamento dos edifícios históricos e culturais no município de Cuiabá-MT, utilizando como ferramenta o sistema de informação geográfica Quantum GIS, para criar um banco de dados cadastrais, manipular e gerar o mapa temático, para servir de base para estudos e projetos de preservação do patrimônio histórico e cultural de Cuiabá-MT, além de enfatizar a história dos principais bens tombados no município. Os pontos geográficos dos bens levantados, assim como o próprio mapa temático gerado, possibilitam a utilização de um banco com dados já tabulados e mapeados, proporcionando maior agilidade no desenvolvimento de projetos que possam otimizar as intervenções de manutenção e preservação do patrimônio histórico e cultural do município e estado.

PALAVRAS-CHAVE: Sensoriamento remoto. Mapeamento. Patrimônio Histórico e Cultural.

\section{SUMMARY}

The most varied technological alternatives have emerged to assist the development of studies and data collection and products that serve as subsidies to various types of projects in various areas. One of these alternatives is the use of geographic information systems for mapping and spatial analysis especially for study in a very large geographic space. Remote sensing is an important instrument in the effectiveness of these studies and in the elaboration of maps with the use of satellite data which facilitates the reach of the results to be applied in architecture and urbanism. The work aimed at mapping historical and cultural buildings in the city of Cuiabá-MT, using as a tool the geographic information system Quantum GIS to create a database of cadastre, manipulate and generate thematic map, to serve as a basis for studies and projects of preservation of the historical and cultural patrimony of Cuiabá-MT, besides emphasizing the history of the main assets registered in the city. The geographic points of the assets raised, as well as the thematic map generated, allow the use of a bank with already tabulated and mapped data providing greater agility in the development of projects that can optimize maintenance interventions and preservation of the historical and cultural patrimony of the county and state.

KEY WORDS: Remote Sensing. Mapping. Historical and Cultural Patrimony.

\section{RESUMEN}

Las más variadas alternativas tecnológicas vienen surgiendo para auxiliar el desarrollo de estudios y levantamiento de datos y productos que sirvan de subsidio a diversos tipos de proyectos de diversas áreas. Una de estas alternativas es la utilización de sistemas de información geográfica para el mapeo y análisis espaciales, principalmente en lo que se refiere al estudio en un espacio geográfico muy extenso. El sensor remoto es un importante instrumento en la efectividad de estos estudios y en la elaboración de mapas con el uso de datos de satélite, lo que facilita el alcance de los resultados a ser aplicados en la arquitectura y urbanismo. El trabajo objetivó el mapeamiento de los edificios históricos y culturales en el municipio de Cuiabá-MT, utilizando como herramienta el sistema de información geográfica Quantum GIS, para crear un banco de datos catastrales, manipular y generar el mapa temático, para servir de base para estudios y proyectos de preservación del patrimonio histórico y cultural de Cuiabá-MT, además de enfatizar la historia de los principales bienes tomados en el municipio. Los puntos geográficos de los bienes levantados, así como el propio mapa temático generado, posibilitan la utilización de un banco con datos ya tabulados y mapeados, proporcionando mayor agilidad en el desarrollo de proyectos que puedan optimizar las intervenciones de mantenimiento y preservación del patrimonio histórico y cultural del país el municipio y el estado.

PALABRAS CLAVE: Sensación remota. Mapeo. Patrimonio Histórico y Cultural. 
futuras gerações, tendo em vista sua previsão legal em diversos instrumentos de proteção, a partir da criação de diversos mecanismos instituídos pelo Iphan, a fim de obter sua adequada gestão.

[...] o Instituto do Patrimônio Histórico e Artístico Nacional (IPHAN $\left.{ }^{1}\right)$ tem atuado para preservar o Centro Histórico de Cuiabá, criando mecanismos de controle das intervenções nos imóveis do conjunto urbano e de orientação ao público, como também para aprofundar parcerias com a prefeitura municipal, especialmente por meio do Instituto de Pesquisa e Desenvolvimento Urbano (IPDU) e da Secretaria de Meio Ambiente e Desenvolvimento Urbano (Smades), esta última no trabalho de fiscalização (PEDROLLO, 2010, p. 6)

Com a finalidade de garantir efetividade aos mecanismos de gestão dos bens históricos e culturais, foi necessário inserir a normatização de proteção do Centro Histórico de Cuiabá em seu Plano Diretor, onde a preservação do patrimônio cultural, configura "como direito da Cidadania e dever da administração pública municipal” (PEDROLLO, 2010, p. 6).

Entretanto, toda essa preocupação em criar instrumentos de proteção aos bens culturais não foi suficiente para coibir a descaracterização do patrimônio existente, pois é crescente a preocupação relacionada a descaracterização do patrimônio em prol da estética comercial nos conjuntos arquitetônico e nas praças históricas de Cuiabá, assim como exposto por Cabral (2018), em entrevista com o arquiteto Robinson Araújo, que relata que a descaracterização da cultura cuiabana é um processo que vem ocorrendo em ciclos arquitetônicos dentro do contexto histórico, os quais foram motivados por processos de colonização, sendo estas mudanças pautadas na ideia de modernização da cidade.

No campo da arquitetura e urbanismo várias alternativas tecnológicas vêm sendo utilizadas para auxiliar no desenvolvimento de estudos e levantamento de dados para o subsídio dos diversos tipos de projetos.

É crescente a utilização de sistemas de informações geográficas para o mapeamento e análises espaciais, principalmente no que se refere a estudo em grandes extensões, como bairros, municípios, estados, dentre outros.

O sensoriamento remoto se apresenta como um importante instrumento na efetivação destes estudos e elaboração de mapas com o uso de dados de satélite, conforme apresentado por Souza (2017), que afirma que o sensoriamento remoto se torna uma alternativa mais ágil e confiável, conforme demonstrado em sua pesquisa, facilitando o alcance dos resultados a serem aplicados na arquitetura e urbanismo.

\section{OBJETIVO}

O trabalho tem por objetivo o mapeamento dos patrimônios históricos e culturais do município de Cuiabá-MT, utilizando como ferramenta o sistema de informação geográfica Quantum GIS, para criar um banco de dados cadastrais, manipular e gerar mapa temático, que possa servir de base para estudos e projetos de preservação do patrimônio histórico e cultural de Cuiabá-MT, além de enfatizar a história dos principais edifícios e espaços tombados no município, ampliando a divulgação de sua história e identidade cultural. 


\section{MATERIAL E MÉTODOS}

Para a realização de levantamento dos bens tombados no município de Cuiabá foi utilizado o Software Quantum GIS, que é um software livre com código-fonte aberto, multiplataforma de sistema de informação geográfica (SIG) que permite a visualização, edição e análise de dados georreferenciados, aplicada a metodologia proposta por Góes e Xavier-da-Silva (1996), que subdivide a etapa em três sendo elas: Pré-Geoprocessamento, Processamento e Pós-Geoprocessamento.

De acordo com Florenzano (2007), o Pré-Geoprocessamento consiste na aquisição e organização dos dados, por meio de levantamento de dados raster do tipo ortofotos, cobrindo a região de Cuiabá.

Para estruturar o banco de dados georreferenciados que serviu de base para a geração dos mapas temáticos, foi disponibilizado pela prefeitura de Cuiabá, na escala 1:100.000, os dados vetoriais dos seguintes temas: limite do município, sistema viário, regiões, setores e bairros.

Após a aquisição dos dados vetoriais, o primeiro passo foi verificar se os bens tombados estavam representados geograficamente na base cartográfica atual do município. Para isso, foi utilizada imagens de alta resolução espacial através do plugin QuickMapServices, que possibilita, entre outras coisas, que se adicione uma camada web (mapas online) a um projeto do QGIS.

No que diz respeito à etapa do processamento, foi realizado o lançamento das coordenadas geográficas, para associar informações aos elementos tombados. Para a inclusão das coordenadas geográficas de cada bem tombado, utilizando a tabela de atributos (atribute table) do QGIS 2.18 ESSEN.

O Pós-Geoprocessamento configurou a fase de criação de mapas com a inserção do tema, legendas, escalas, configuração dos textos e a criação dos layouts. A organização, produção e interpretação dos dados foram armazenadas em um banco de dados digital. (LONGLEY et al, 2013).

Após o mapeamento foi realizado o levantamento bibliográfico acerca da história dos principais e mais representativos edifícios e espaços históricos tombados no município de Cuiabá-MT, relacionando um breve contexto histórico sobre cada um.

\section{RESULTADOS}

Após o levantamento e identificação dos bens tombados em Cuiabá-MT, os mesmos foram relacionados conforme disposto no quadro 1 , juntamente com os dados do ano de construção, ato de tombamento, ocupação atual, seu endereço e as coordenadas geográficas que serviram de base para o mapeamento. 


\section{ANAP

\section{REVISTA CIENTÍFICA}

\begin{tabular}{|c|c|c|c|c|c|c|c|}
\hline $\mathbf{N}^{\circ}$ & Bens Tombados & $\begin{array}{l}\text { Ano de } \\
\text { Const. }\end{array}$ & $\begin{array}{c}\text { Ato de } \\
\text { Tombamento }\end{array}$ & Ocupação Atual & Endereço & $\begin{array}{c}\text { Coord. } \\
\mathrm{X}\end{array}$ & $\begin{array}{c}\text { Coord. } \\
\text { Y }\end{array}$ \\
\hline 1 & $\begin{array}{l}\text { 44. } \text { Batalhão de } \\
\text { Infantaria } \\
\text { Motorizada }\end{array}$ & 1941 & Portaria 52/07 & $\begin{array}{l}\text { 44. . Batalhão de } \\
\text { Infantaria } \\
\text { Motorizada }\end{array}$ & $\begin{array}{c}\text { Avenida José M. de } \\
\text { Figueiredo, bairro Duque de } \\
\text { Caxias }\end{array}$ & 595534 & 8276179 \\
\hline 2 & $\begin{array}{l}\text { Antigo Quartel } \\
\text { da Força Pública }\end{array}$ & $\begin{array}{l}\text { Séc. } \\
\text { XVIII }\end{array}$ & Portaria $12 / 98$ & $\begin{array}{c}\text { Ganha Tempo } \\
\text { (Setec/MT) }\end{array}$ & $\begin{array}{c}\text { Rua } 13 \text { de Junho, esquina } \\
\text { com Travessa Paes de } \\
\text { Oliveira, s/n, bairro Centro } \\
\text { Sul }\end{array}$ & 596742 & 8274960 \\
\hline 3 & $\begin{array}{c}\text { Arsenal de } \\
\text { Guerra }\end{array}$ & $\begin{array}{c}1819 \text { a } \\
1832 \\
\end{array}$ & Portaria $63 / 83$ & $\begin{array}{c}\text { Espaço Cultural } \\
\text { Sesc-Arsenal }\end{array}$ & $\begin{array}{l}\text { Rua } 13 \text { de Junho, bairro } \\
\text { Centro Sul, Cuiabá - MT }\end{array}$ & 596073 & 8274171 \\
\hline 4 & $\begin{array}{c}\text { Assembleia } \\
\text { Legislativa } \\
\text { Provincial de } \\
\text { Mato Grosso }\end{array}$ & 1776 & Portaria 38/84 & $\begin{array}{l}\text { Secretaria de } \\
\text { Estado de } \\
\text { Desenv. do } \\
\text { Turismo }\end{array}$ & $\begin{array}{l}\text { Rua Voluntários da Pátria, } \\
\text { 118, Bairro Centro Norte }\end{array}$ & 597171 & 8275647 \\
\hline 5 & Cadeia Pública & $\begin{array}{c}1858 \text { a } \\
1862\end{array}$ & Portaria 55/83 & $\begin{array}{l}\text { Fund. Centro de } \\
\text { Reabilitação D. } \\
\text { Aquino Correa }\end{array}$ & $\begin{array}{l}\text { Rua Joaquim Murtinho, } \\
\text { 1556, Bairro Centro Sul }\end{array}$ & 595905 & 8274356 \\
\hline 6 & $\begin{array}{l}\text { Casa Barão de } \\
\text { Melgaço }\end{array}$ & $\begin{array}{l}\text { Séc. } \\
\text { XVIII }\end{array}$ & Portaria $13 / 98$ & $\begin{array}{l}\text { Instituto Hist. e } \\
\text { Geogr. de Mato } \\
\text { Grosso e } \\
\text { Academia Mato- } \\
\text { Grossense de } \\
\text { Letras }\end{array}$ & $\begin{array}{c}\text { Rua Barão de Melgaço, } \\
\text { esquina com Voluntários da } \\
\text { Pátria } 3869, \text { bairro Centro } \\
\text { Norte }\end{array}$ & 596957 & 8275715 \\
\hline 7 & Casa Cuiabana & $\begin{array}{l}\text { Final do } \\
\text { séc. } \\
\text { XVIII }\end{array}$ & Portaria 27/83 & $\begin{array}{l}\text { Espaço Cultural } \\
\text { da Secr. de } \\
\text { Estado de } \\
\text { Cultura } \\
\end{array}$ & $\begin{array}{c}\text { Rua General Vale 181, bairro } \\
\text { Bandeirantes }\end{array}$ & 597153 & 8274819 \\
\hline 8 & $\begin{array}{l}\text { Casa Dom } \\
\text { Aquino }\end{array}$ & 1842 & Portaria 08/97 & $\begin{array}{l}\text { Museu de Pré- } \\
\text { História }\end{array}$ & $\begin{array}{c}\text { Avenida Manoel José de } \\
\text { Arruda 2000, Bairro Jardim } \\
\text { Europa }\end{array}$ & 597493 & 8272359 \\
\hline 9 & $\begin{array}{l}\text { Casa dos Frades } \\
\text { Franciscanos }\end{array}$ & Séc. XIX & Portaria 77/87 & Casa Paroquial & $\begin{array}{c}\text { Rua Cândido Mariano, Praça } \\
\text { Antônio Correa, B. Centro } \\
\text { Norte }\end{array}$ & 596647 & 8275745 \\
\hline 10 & $\begin{array}{l}\text { Casarão de } \\
\text { Nhonhô de } \\
\text { Manduca, Dona } \\
\text { Codó e Dona } \\
\text { Bembem }\end{array}$ & $\cdots$ & Portaria 13/98 & Residencial & $\begin{array}{c}\text { Rua Barão de Melgaço, } \\
\text { bairro Centro Norte }\end{array}$ & 597027 & 8275817 \\
\hline 11 & $\begin{array}{l}\text { Catedral Basílica } \\
\text { do Senhor Bom } \\
\text { Jesus de Cuiabá }\end{array}$ & 1722 & --- & Religiosa & $\begin{array}{c}\text { Praça da República, s/n, } \\
\text { bairro Centro Norte }\end{array}$ & 596909 & 8275363 \\
\hline 12 & $\begin{array}{c}\text { Chafariz do } \\
\text { Mundéu }\end{array}$ & 1871 & Portaria 32/79 & Monumento & $\begin{array}{c}\text { Praça Bispo Dom José, bairro } \\
\text { Centro Norte }\end{array}$ & 596948 & 8275088 \\
\hline 13 & $\begin{array}{c}\text { Cine-Teatro } \\
\text { Cuiabá }\end{array}$ & 1942 & Portaria $31 / 84$ & Em reforma & $\begin{array}{c}\text { Avenida Getúlio Vargas, 247, } \\
\text { bairro Centro Norte }\end{array}$ & 596828 & 8275430 \\
\hline 14 & $\begin{array}{l}\text { Conjunto } \\
\text { Arquitetônico do } \\
\text { Antigo Distrito D. } \\
\text { Pedro II, Porto } \\
\end{array}$ & $\begin{array}{l}\text { a partir } \\
\text { de } 1720\end{array}$ & $\begin{array}{c}\text { Portaria n.o } \\
\text { 035/SEC/2007 }\end{array}$ & $\begin{array}{l}\text { Comércio e } \\
\text { Residências }\end{array}$ & Bairro do Porto & 595723 & 8273614 \\
\hline 15 & $\begin{array}{c}\text { Fachada da Santa } \\
\text { Casa de }\end{array}$ & $\begin{array}{l}\text { Início } \\
\text { do séc. }\end{array}$ & Portaria 14/98 & Hospital & $\begin{array}{c}\text { Praça do Seminário, bairro } \\
\text { Dom Aquino }\end{array}$ & 597005 & 8274807 \\
\hline
\end{tabular}




\section{ANAP

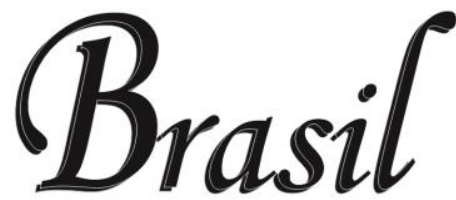

\section{REVISTA CIENTÍFICA}

\begin{tabular}{|c|c|c|c|c|c|c|c|}
\hline & Misericórdia & XIX & & & & & \\
\hline 16 & $\begin{array}{l}\text { Fachada do } \\
\text { Cemitério da } \\
\text { Piedade }\end{array}$ & 1875 & Portaria 15/98 & Cemitério & $\begin{array}{c}\text { Rua Batista das Neves } 489, \\
\text { bairro Centro Norte }\end{array}$ & 596822 & 8275954 \\
\hline 17 & Grande Hotel & 1940 & Portaria $61 / 83$ & $\begin{array}{l}\text { Secretaria de } \\
\text { Estado de } \\
\text { Cultura }\end{array}$ & $\begin{array}{c}\text { Avenida Getúlio Vargas 247, } \\
\text { bairro Centro Norte }\end{array}$ & 596857 & 8275409 \\
\hline 18 & $\begin{array}{l}\text { Grupo Escolar } \\
\text { Senador Azeredo }\end{array}$ & 1910 & Portaria 57/83 & Casa do Artesão & $\begin{array}{c}\text { Rua Senador Metelo, } \\
\text { esquina com } 13 \text { de junho, } \\
\text { 1746, bairro do Porto }\end{array}$ & 595927 & 8274058 \\
\hline 19 & $\begin{array}{l}\text { Igreja da Boa } \\
\text { Morte }\end{array}$ & $\begin{array}{l}1 . \underline{a} \\
\text { metade } \\
\text { séc. XIX }\end{array}$ & Portaria 75/87 & Religiosa & $\begin{array}{c}\text { Praça Antônio Correa, bairro } \\
\text { Centro Norte }\end{array}$ & 596717 & 8275759 \\
\hline 20 & $\begin{array}{l}\text { Igreja de São } \\
\text { Gonçalo }\end{array}$ & $\begin{array}{c}1782 \mathrm{a} \\
1916\end{array}$ & Portaria 74/87 & Religiosa & $\begin{array}{l}\text { Rua XV de Novembro, } \\
\text { esquina com Senador } \\
\text { Metelo, bairro Centro Sul }\end{array}$ & 596120 & 8273898 \\
\hline 21 & Igreja do Rosário & $\begin{array}{c}1750 \mathrm{a} \\
1751 \\
\end{array}$ & Portaria 76/87 & Religiosa & $\begin{array}{c}\text { Praça do Rosário, bairro da } \\
\text { Lixeira }\end{array}$ & 597362 & 8275650 \\
\hline 22 & $\begin{array}{l}\text { Igreja N. }{ }^{\text {a S. }} \text { a do } \\
\text { Bom Despacho }\end{array}$ & 1918 & Portaria 47/77 & Religiosa & $\begin{array}{c}\text { Praça do Seminário, bairro } \\
\text { Dom Aquino }\end{array}$ & 596892 & 8274902 \\
\hline 23 & $\begin{array}{c}\text { Igreja Senhor dos } \\
\text { Passos }\end{array}$ & 1792 & $\begin{array}{c}\text { Processo de } \\
\text { tombamento } \\
\text { no } 1180-\mathrm{T} \text { - } \\
85 / 93\end{array}$ & Religiosa & $\begin{array}{c}\text { Rua } 7 \text { de Setembro, 2, bairro } \\
\text { Centro Norte }\end{array}$ & 597221 & 8275600 \\
\hline 24 & Liceu Cuiabano & 1944 & Portaria 59/83 & $\begin{array}{c}\text { Estabelecimento } \\
\text { de ensino }\end{array}$ & $\begin{array}{c}\text { Praça General Mallet, } 150, \\
\text { bairro do Quilombo }\end{array}$ & 596309 & 8275892 \\
\hline 25 & $\begin{array}{l}\text { Mercado do } \\
\text { Peixe }\end{array}$ & 1781 & Portaria 26/83 & $\begin{array}{l}\text { Museu do Rio } \\
\text { Hid Alfredo Scaff }\end{array}$ & $\begin{array}{c}\text { Avenida Manoel J. de } \\
\text { Arruda, 1899, bairro Porto }\end{array}$ & 595660 & 8273464 \\
\hline 26 & $\begin{array}{l}\text { Palácio da } \\
\text { Instrução }\end{array}$ & $\begin{array}{c}1911 \text { a } \\
1913\end{array}$ & Portaria 03/83 & $\begin{array}{l}\text { Museu e } \\
\text { biblioteca }\end{array}$ & $\begin{array}{c}\text { Rua Antônio Maria Coelho, } \\
\text { 151, Praça da República, } \\
\text { bairro Centro Norte }\end{array}$ & 596879 & 8275320 \\
\hline 27 & Palácio da Justiça & $\begin{array}{l}\text { Dec. } 40 \\
\text { séc. } X X\end{array}$ & Portaria 05/00 & Juizado Especial & $\begin{array}{c}\text { Avenida Getúlio Vargas, } 450, \\
\text { bairro Centro Norte }\end{array}$ & 596731 & 8275580 \\
\hline 28 & Palácio Episcopal & $\cdots$ & Portaria 08/98 & $\begin{array}{c}\text { Residência dos } \\
\text { Bispos }\end{array}$ & $\begin{array}{c}\text { Praça do Seminário, bairro } \\
\text { Dom Aquino }\end{array}$ & 596938 & 8274793 \\
\hline 29 & $\begin{array}{l}\text { Residência Oficial } \\
\text { dos } \\
\text { Governadores }\end{array}$ & 1941 & Portaria 58/83 & MT Fomento & $\begin{array}{c}\text { Rua Barão de Melgaço, 3565, } \\
\text { bairro Centro Norte }\end{array}$ & 596881 & 8275526 \\
\hline 30 & Secretaria Geral & $\begin{array}{l}\text { Anos } 40 \\
\text { séc. } X X\end{array}$ & Portaria 07/00 & $\begin{array}{l}\text { Arquivo Público } \\
\text { do Estado de MT }\end{array}$ & $\begin{array}{c}\text { Av. Getúlio Vargas, bairro } \\
\text { Centro Norte }\end{array}$ & 596705 & 8275548 \\
\hline 31 & $\begin{array}{l}\text { Seminário da } \\
\text { Conceição }\end{array}$ & $\begin{array}{c}1858 \text { a } \\
1882 \\
\end{array}$ & Portaria $47 / 77$ & $\begin{array}{l}\text { Museu Histórico } \\
\text { de Mato Grosso }\end{array}$ & $\begin{array}{c}\text { Praça do Seminário, bairro } \\
\text { Dom Aquino }\end{array}$ & 596913 & 8274872 \\
\hline 32 & $\begin{array}{c}\text { Thesouro do } \\
\text { Estado }\end{array}$ & $\begin{array}{c}1896 \text { a } \\
1898\end{array}$ & Portaria 03/83 & $\begin{array}{l}\text { Secretaria de } \\
\text { Estado de Des. } \\
\text { do Turismo }\end{array}$ & $\begin{array}{l}\text { Praça da República, 131, } \\
\text { bairro Centro Norte }\end{array}$ & 596908 & 8275282 \\
\hline
\end{tabular}

Fonte: Prefeitura de Cuiabá, 2010. Adequado pelos autores.

\subsection{Contexto histórico de alguns bens tombados}

Vários edifícios históricos carregam a história e a cultura cuiabana, dentre eles, alguns se destacam pela sua representatividade, como a Igreja do Rosário (Figura 1A), que segundo dados do Iphan (2019), foi construída em 1730 em adobe, e é considerada a mais antiga igreja e um dos marcos de fundação de Cuiabá. A fachada é típica da arquitetura colonial brasileira, 


\section{ANAP

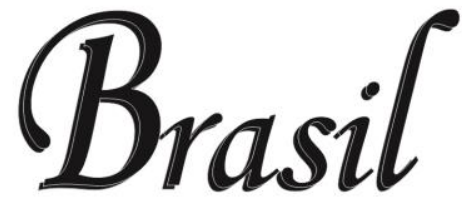 \\ ISSN 1984-3240 v. 12, n. 27}

\section{REVISTA CIENTÍFICA 2019}

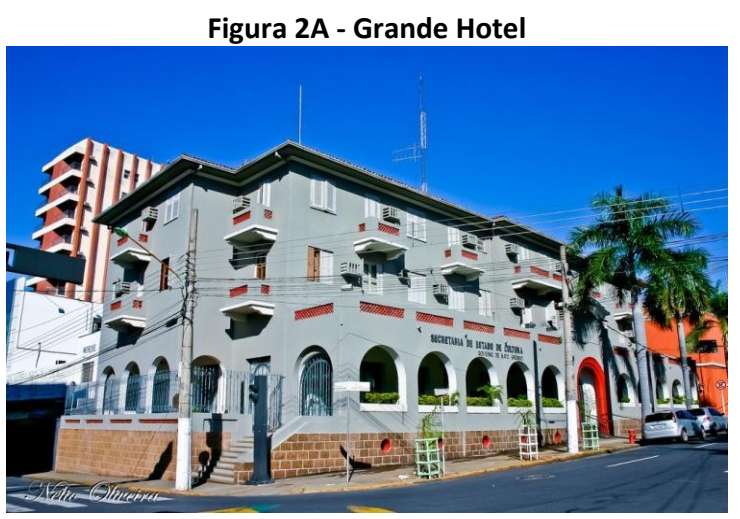

Fonte: Disponível em: mt.gov.

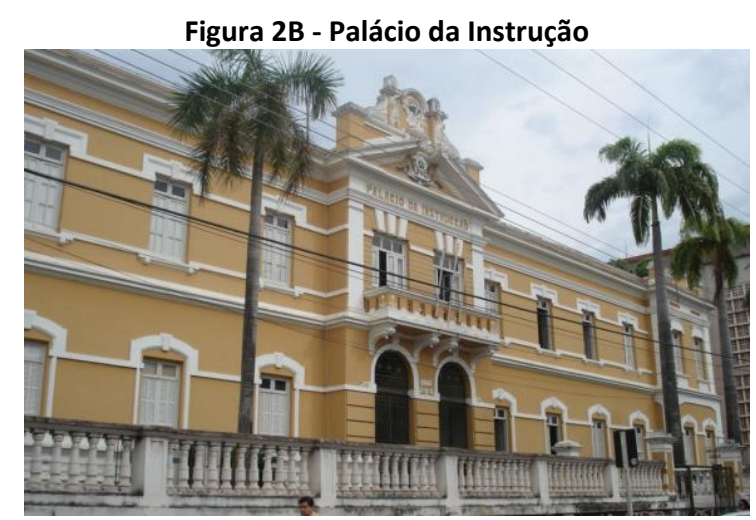

Fonte: Disponível em: Matogrosso mais.

O Palácio da Instrução (Figura 2B) está situado na Praça da República no Centro de Cuiabá também se destaca como edifício histórico, abrigando atualmente um museu e a biblioteca pública. Segundo dados do Iphan (2019), foi inaugurado em 1913, a construção seguia a arquitetura da época, com alicerces em pedra canga e cristal, paredes de adobe, com 80 centímetros de largura. Já abrigou as escolas Liceu Cuiabano, Normal, Modelo Barão de Melgaço e o Museu de História Nacional e Antropologia.

A Casa do Artesão (Figura 3A), bem como o antigo Arsenal de Guerra (Figura 3B), hoje são espaços destinados a promoção de ações culturais e valorizam a história e cultura local e matogrossense.

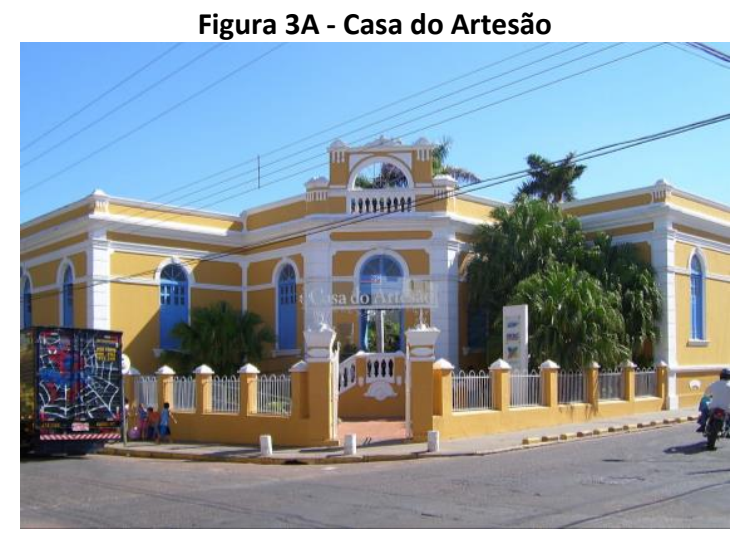

Fonte: Disponível em: Matogrosso mais.

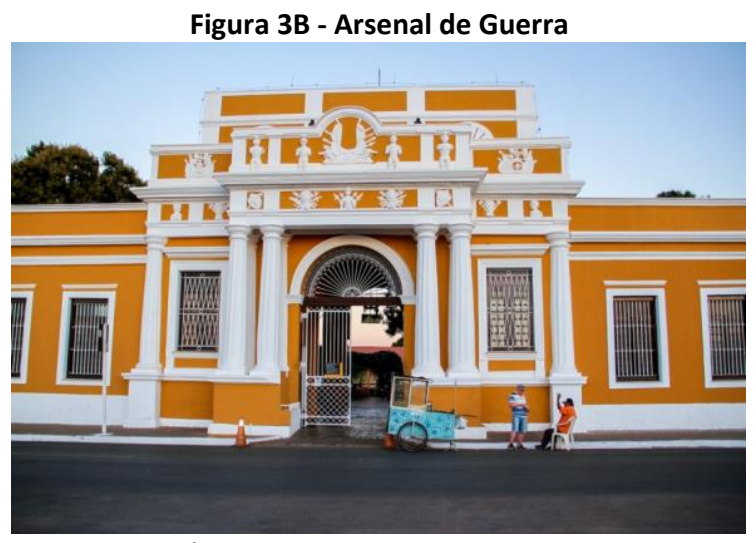

Fonte: Disponível em: Espaço-cultural-sesc-arsenal.

Inaugurada em 10/09/1910 com o nome de Grupo Escolar Senador Azeredo a Casa do Artesão, abrigou o antigo Grupo Escolar do 2 Distrito-Porto, posteriormente teve suas edificações tombadas em 1983 pela Fundação Cultural de Mato Grosso (SEDEC, 2019). O edifício possui uma linha construtiva simples e ainda conserva as características originais da construção. Funcionou como estabelecimento de ensino desde a sua inauguração até o ano de 1975 quando passou a abrigar a Casa do Artesão. 


\section{ANAP

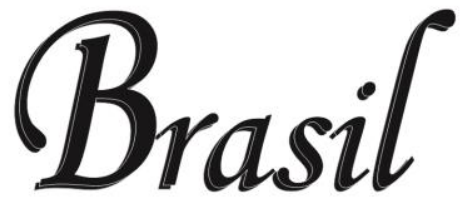 \\ ISSN 1984-3240 v. 12, n. 27}

Segundo o Iphan (2019), o Arsenal de Guerra foi criado com o nome Real Trem de Guerra, por Carta Régia de D. João VI em 1818, era destinado para o conserto e fabricação de armas militares. A construção teve início em 1819 e ficou pronta em 1832, foram empregadas técnicas construtivas e materiais da região. Em 1831 por determinação legal, foi criado o Arsenal de Guerra da Província de Mato Grosso, o edifício foi ampliado e adaptado em 1848.

De acordo com a Sedec (2019), o Arsenal de Guerra com seu estilo neoclássico franco-lusitano, abriu suas portas em agosto de 2001 como Centro de Atividades SESC Arsenal oportunizando os artistas locais com espaços destinados ao lazer da sociedade cuiabana.

No Mercado do Peixe (Figura 4A) está o museu do rio, localiza-se no bairro do Porto, bem como o conjunto arquitetônico do Porto (Figura 4B) que é uma das partes mais antigas da cidade e que recebeu na revitalização da orla do Porto algumas réplicas dos edifícios históricos que representam as características do bairro.

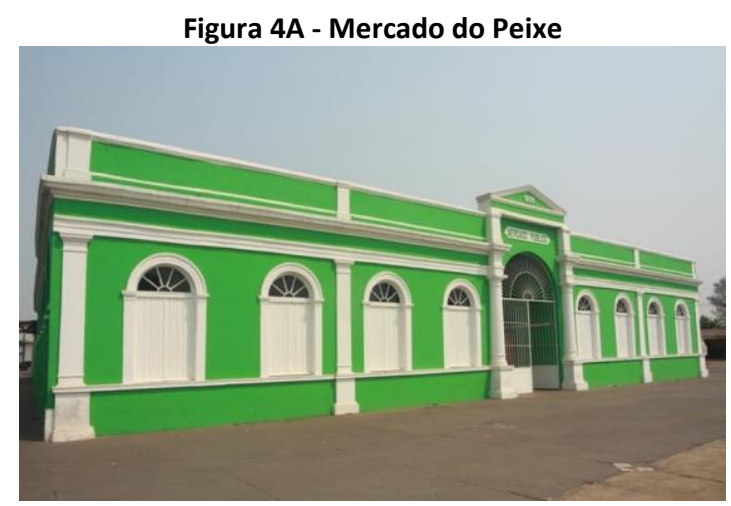

Fonte: Disponível em: Deville.com.br

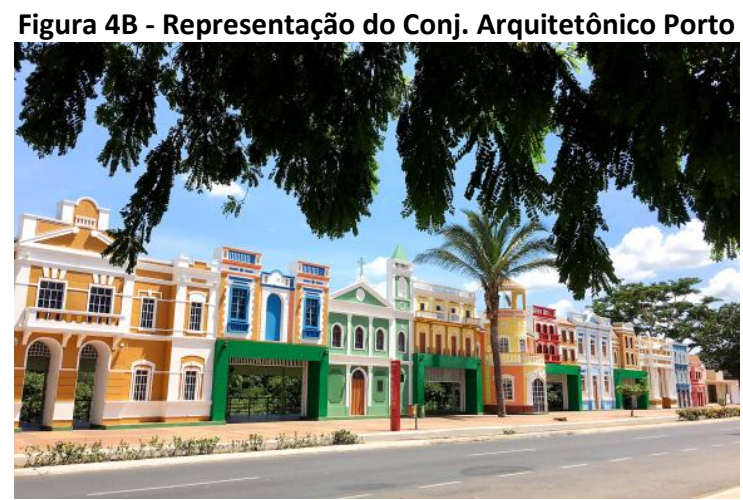

Fonte: Disponível em: Portal Matogrosso.

O Mercado do Peixe, construído em 1899, foi recuperado em 1999 para abrigar o Museu do Rio Cuiabá Hid Alfredo Scaff, um morador da região que explorou por muito tempo a navegação fluvial no rio Cuiabá, além de ter sido considerado o principal negociante do antigo mercado. (IPHAN, 2019)

De acordo com Ariano (2013), o edifício possui estilo neoclássico e foi construído utilizando materiais disponíveis na época, é considerado um marco de grande importância para a região.

O bairro do Porto, conforme Aguiar (2017), passou por um processo de deterioração dentro do contexto histórico, atualmente alguns pontos históricos da região foram revitalizados, como é o caso da orla do Rio Cuiabá. No início do Porto era possível fazer o trajeto através da navegação, o que durou até o séc. XX, deixando nesta região características urbanas e arquitetônicas neoclássicas, típicas da época, como os edifícios alinhados nas fachadas e próximas às vias de circulação.

Outros edifícios tombados que também são importantes e representativos para a história e cultura local estão relacionados a seguir com um breve contexto histórico, conforme disposto nos sites da Secretaria de Estado de Desenvolvimento Econômico - SEDEC e do Iphan. 

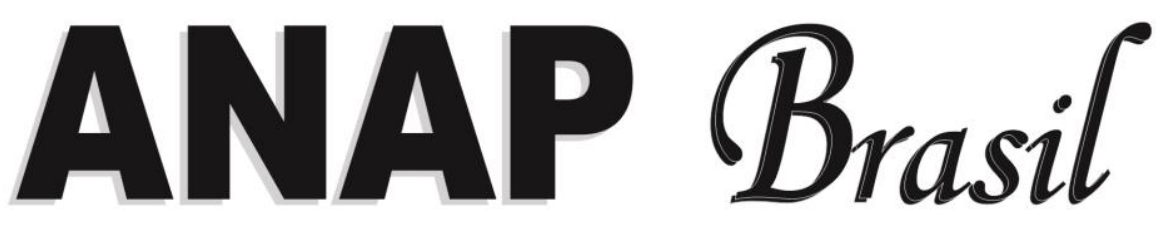

\section{Cadeia Pública}

O prédio da antiga Cadeia Pública de Cuiabá foi construído em 1858 a 1862, e os materiais empregados na construção dos alicerces são em pedra canga até cinco palmos acima do chão, com as paredes de adobe e o muro continuado com taipa. Funcionou como Cadeia Pública até 1975, quando foi transferida para o Presídio Central. (SEDEC, 2019)

\section{Casa Barão de Melgaço}

Inaugurado em 1802, o Casarão foi residência do Almirante Augusto João Manoel Leverger, o Barão de Melgaço em 1830. Após o falecimento do Barão em 1880, sua herdeira doa a casa para a sobrinha que em 1926 tem o imóvel desapropriado pelo Estado. Em 1931 o Estado de Mato Grosso doa o bem para a sede do Instituto Histórico e Geográfico e a Academia Mato-grossense de Letras, que atualmente utiliza o edifício. (SEDEC, 2019)

\section{Casa Cuiabana}

O edifício foi construído no século XVIII em taipa e adobe, com alicerces em pedra canga e um dos principais detalhes é a manutenção da ambiência de um quintal cuiabano tradicional. Atualmente é utilizada pela Secretaria de Estado de Cultura, oferecendo cursos e oficinas. (SEDEC, 2019)

\section{Casa Dom Aquino}

Construído em 1842 em estilo colonial e formato de U, o imóvel abriga o museu de pré-história inaugurado em dezembro de 2006. Na casa nasceram duas personalidades, Dom Aquino, que foi bispo, arcebispo, governador de província, escritor e poeta, e Joaquim Murtinho, que foi político, engenheiro e médico, precursor da Medicina Homeopática no Brasil. (IPHAN, 2019)

\section{Casarão de Nhonhô de Manduca, Dona Codó e Dona Bembem}

O Casarão é conhecido como um dos mais tradicionais e confortáveis, tipicamente cuiabano. Retrata na sua construção todo o aconchego e receptividade do povo cuiabano. A partir de 1974 a escolheram como a mais típica casa cuiabana para realização anual da festa do glorioso Santo, o que permaneceu até 1981. Atualmente encontra-se em reforma. (SEDEC, 2019)

\section{Catedral Basilica do Senhor Bom Jesus de Cuiabá}

Construída em 1722, passou por diversas reformas e construções, após a construção de uma nova torre o templo deixou de ser Matriz e tornou-se Catedral. A edificação original foi demolida em 1968, e em seu lugar foi erguido o templo atual. No subsolo há uma cripta onde estão enterradas autoridades da Igreja e o fundador de Cuiabá Pascoal Moreira Cabral. (IPHAN, 2019)

\section{Cine-Teatro Cuiabá}

Inaugurado em 1942, o espaço cultural foi tombado em 1984, passou por grandes reformas e o espaço manteve suas características arquitetônicas da época em que foi construído, o centro cultural marcou a história de Cuiabá dando uma nova conotação no que diz respeito ao aspecto 

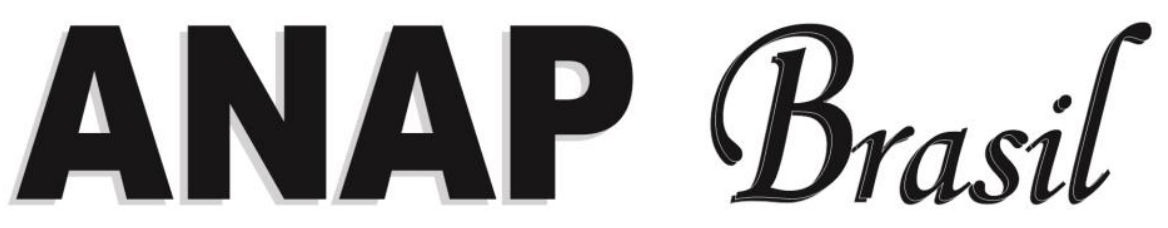

social, cultural e econômico. (SEDEC, 2019)

Igreja da Boa Morte

A igreja é bicentenária, uma verdadeira relíquia de Cuiabá, é caracterizada por um único telhado em duas águas e composição arquitetônica barroca com fachada neoclássica realçada pela sua posição no alto de um platô. Possui uma arquitetura simples que se destaca na paisagem urbana, carrega em sua história grandes tradições e manifestações de fé. (SEDEC, 2019)

\section{Igreja de São Gonçalo}

O início da construção se deu em 1782, é primeira capela na Freguesia de D. Pedro II. Ao longo dos anos, o templo passou por diversas reformas até chegar à composição arquitetônica que começa a ser definida em 1894, caracterizando o estilo colonial - neoclássico. Em 1916 foi incorporado seu último adereço, a imagem do Cristo Redentor. (SEDEC, 2019)

\section{Igreja Senhor dos Passos}

Guarda muitas histórias e lendas, a planta da igreja é tipicamente colonial, dividida em nave e capela-mor, na fachada principal localiza-se a torre sineira e é um dos mais belos e admirados patrimônios de Cuiabá. (IPHAN, 2019)

\section{Liceu Cuiabano}

Construído em 1944, faz parte das Obras Oficiais do Governo Getúlio Vargas e marcou uma nova fase na instrução e ensino dos jovens mato-grossenses, sendo equipado com mobiliário adequado e laboratórios de física e química, campo de futebol, anfiteatro, entre outros. (SEDEC, 2019)

\section{Palácio da Justiça}

Inaugurado no ano de 1942, foi uma obra bastante econômica, foram utilizadas sobras de materiais de outras obras oficiais, possui elementos que caracterizam o estilo art-dèco, e foi construído para o funcionamento do Tribunal de Justiça, Tribunal do Júri e Cartório. (SEDEC, 2019)

\section{Residência Oficial dos Governadores}

Construída entre os anos de 1939 e 1941, a residência abrigou 14 dirigentes do Estado de Mato Grosso e seus familiares durante 45 anos e foi desativada em 1986. A última reforma/restauro ocorreu em 2000 e devolveu à residência suas características do projeto original. (SEDEC, 2019)

\section{Seminário da Conceição}

Construído em 1858, é considerado um dos principais prédios do patrimônio histórico de Mato Grosso. A edificação possui característica da arquitetura colonial, com paredes de adobe e divisórias de pau-a-pique. Já foi enfermaria durante a epidemia de varíola em 1867. (SEDEC, 2019) 


\subsection{Mapeamento dos bens tombados}

Atualmente uma parte dos bens tombados em Cuiabá estão sendo utilizados para outras finalidades que não as originais da época de suas construções, conforme disposto no quadro 1. Dos 32 bens tombados, atualmente $25 \%$ estão sendo utilizados para fins religiosos, $25 \%$ utilizados pelas instituições públicas, $12 \%$ utilizados como museus, $13 \%$ utilizados como espaços culturais, $6 \%$ utilizados como estabelecimentos de ensino e $6 \%$ utilizados como residências, conforme apresentado na Figura 5.

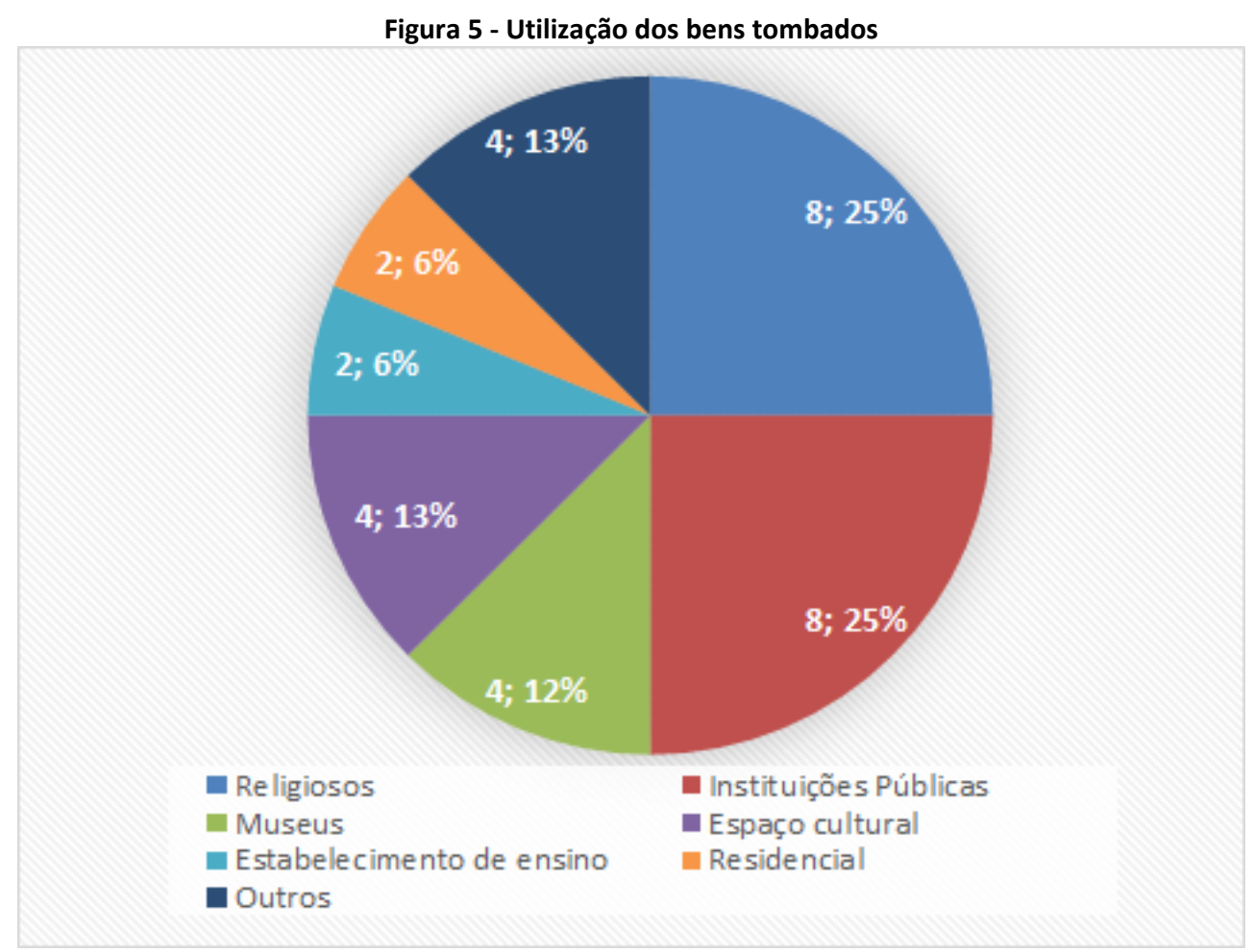

Fonte: Elaborado pelos autores, 2019.

A partir do levantamento dos dados e da utilização do Sistema de informação geográfica (SIG) foi possível a visualização, edição e análise de dados georreferenciados, realizando a espacialização dos bens tombados, resultando em um mapa temático, conforme Figura 6 . 


\section{ANAP

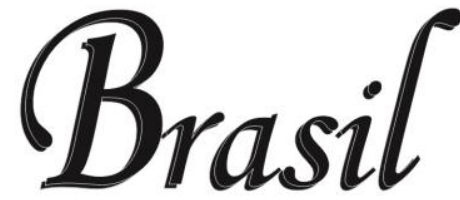 \\ ISSN 1984-3240 v. 12, n. 27}

\section{REVISTA CIENTÍFICA 2019}

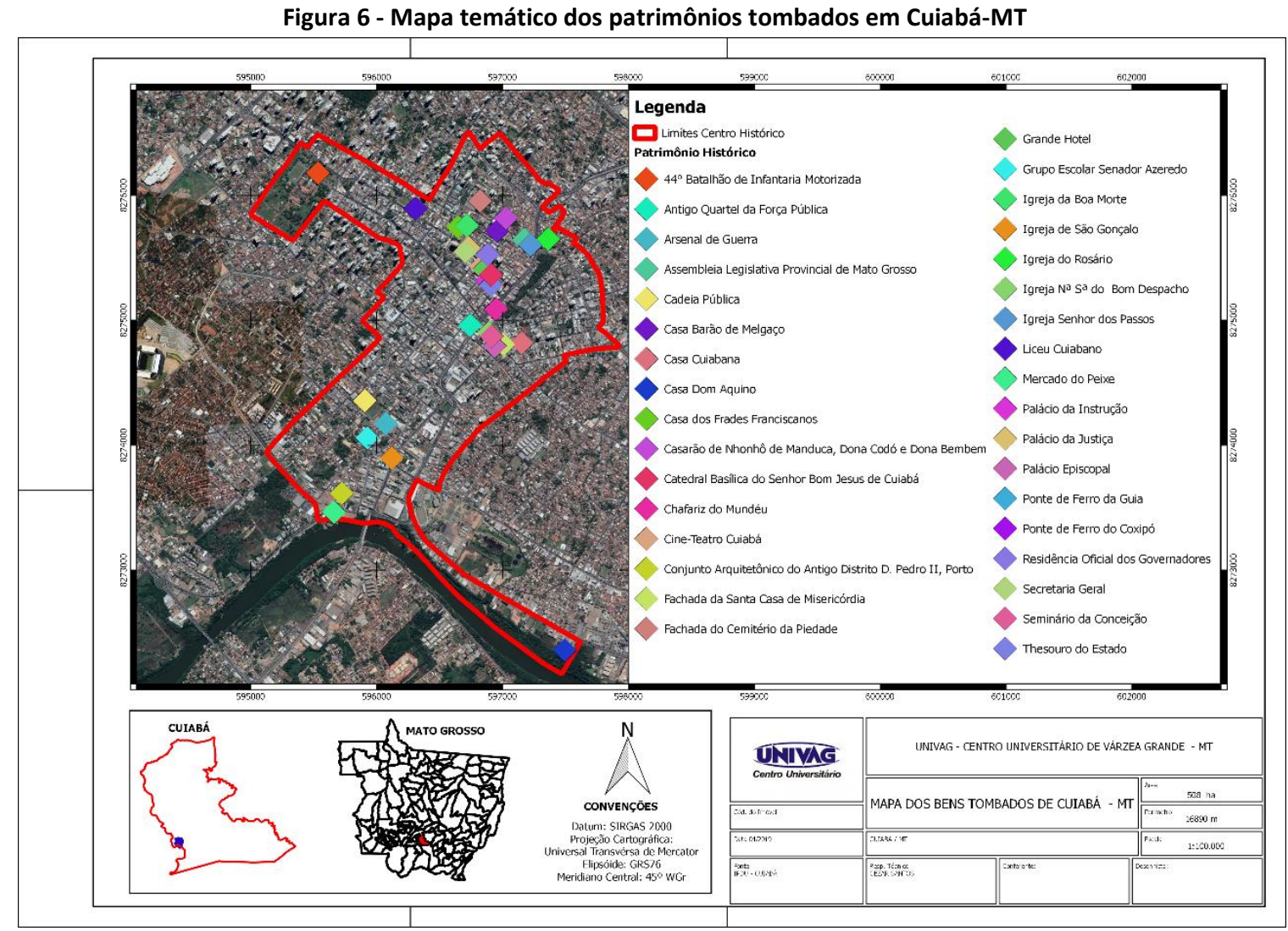

Fonte: Elaborado pelos autores utilizando o Sistema Quantum GIS, 2019.

Com o mapa temático gerado, é possível fazer um recorte espacial da distribuição dos bens do patrimônio histórico e cultural tombados no município. O mapa elaborado, também permitiu observar que os bens tombados estão, na sua maioria, na parte central de Cuiabá, provavelmente devido ao início da ocupação espacial do município ter se dado nesta região central e mais próxima ao rio.

Os bens dispostos no mapa possuem grande representatividade para o município, pois refletem a cultura e história cuiabana e mato-grossense, assim como pode subsidiar a proposição de projetos que visem a sua restauração e manutenção, os quais são primordiais para manter viva a história e cultura local.

\section{CONCLUSÃo}

A utilização cada vez maior de ferramentas e sistemas que proporcionem a consolidação de dados geográficos e os transformem em mapas temáticos são importantes para várias áreas do saber, assim como no campo da arquitetura e urbanismo, pois proporcionam maior agilidade e confiabilidade nas informações e mapas gerados.

Os pontos geográficos dos bens históricos e culturais de Cuiabá e o próprio mapa temático gerado, possibilitará a utilização de um banco com dados já tabulados, proporcionando maior agilidade no desenvolvimento de projetos que venham a otimizar as formas de manutenção e 
SECRETARIA DE ESTADO DE DESENVOLVIMENTO ECONÔMICO - SEDEC. Monumentos Históricos. Mato Grosso.

Disponível em: <http://www.sedec.mt.gov.br/-/3027115-monumentos-historicos?inheritRedirect=true>. Acesso em: 17 Abr. 2019.

SILVA, Luciana Paschoal Hoffmann da. Geoprocessamento aplicado à realidade do patrimônio histórico do bairro Savassi/Centro de Belo Horizonte. Monografia - Universidade Federal de Minas Gerais. Belo Horizonte, 2002. n. p.74. Disponível em: <http://www.csr.ufmg.br/geoprocessamento/publicacoes/LUCIANA\%20PASCHOAL\%20HOFFMANN \%20DA\%20SILVA.PDF>. Acesso em: 17 Mar. 2019.

SOUZA, A. S.; FERREIRA, L. S.; DUARTE, D. H. S. Aplicações do sensoriamento remoto para estudos em arquitetura e urbanismo: subsídios para correlações entre dados remotos e medições de solo. Faculdade de Arquitetura e Urbanismo da Universidade de São Paulo - FAUUSP, São Paulo - SP, 2017. Disponível em: <

http://marte2.sid.inpe.br/col/sid.inpe.br/marte2/2017/10.27.15.49.14/doc/60214.pdf>. Acesso em: 17 Mar. 2019.

XAVIER-DA-SILVA, J.; CARVALHO FILHO, L. M. Sistemas de Informação Geográfica: uma proposta metodológica. In: CONFERÊNCIA LATINO-AMERICANA SOBRE SISTEMAS DE INFORMAÇÃO GEOGRÁFICA, IV., SIMPÓSIO BRASILEIRO DE GEOPROCESSAMENTO, II., 1993, São Paulo. Anais... São Paulo: Universidade de São Paulo, 1993. v. 1, p. 609-628. 